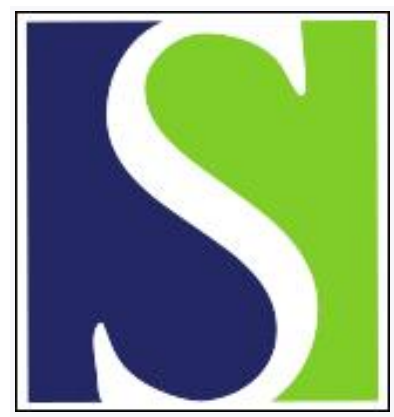

Scand J Work Environ Health 2015;41(1):54-64

https://doi.org/10.5271/sjweh.3463

Published online: 13 Oct 2014, Issue date: 01 Jan 2015

Lifestyle counseling to reduce body weight and cardiometabolic risk factors among truck and bus drivers - a randomized controlled trial

by Puhkala J, Kukkonen-Harjula K, Mansikkamäki K, Aittasalo M, Hublin C, Kärmeniemi P, Olkkonen S, Partinen M, Sallinen M, Tokola K, Fogelholm M

Our aim was to decrease body weight and cardiometabolic risk factors among overweight truck and bus drivers by structured lifestyle counseling. Our study is one of the few randomized trials to promote health of professional drivers. The study showed clinically meaningful decreases in body weight and cardiometabolic risk factors after 12 months of counseling followed by 12 months of follow-up.

Affiliation: UKK Institute for Health Promotion Research, Box 30, FI-33501 Tampere, Finland.[E-mail: jatta.puhkala@uta.fi]

Refers to the following texts of the Journal: 2013;39(3):233-240

2011;37(4):263-275 2010;36(2):150-162 2010;36(2):96-108

2010;36(3):202-215 1993;19(5):326-333

The following articles refer to this text: 2019;45(4):321-323; 2020;46(1):1-4

Key terms: body weight; bus driver; cardiometabolic risk factor; exercise; lifestyle counseling; MeS; metabolic syndrome; nutrition; obesity; professional driver; randomized controlled trial; risk factor; truck driver; walking; weight loss

This article in PubMed: www.ncbi.nlm.nih.gov/pubmed/25310464

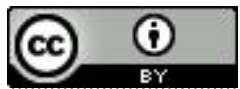




\title{
Lifestyle counseling to reduce body weight and cardiometabolic risk factors among truck and bus drivers - a randomized controlled trial
}

\author{
Jatta Puhkala, MSc, ${ }^{1}$ Katriina Kukkonen-Harjula, DMedSc, ${ }^{1}$ Kirsi Mansikkamäki, MSc, ${ }^{1,}$ 'Minna Aittasalo, \\ DSc, ${ }^{1}$ Christer Hublin, DMedSc, ${ }^{3}$ Paula Kärmeniemi, MSc, ${ }^{3}$ Seppo Olkkonen, DMedSc, ${ }^{3}$ Markku Partinen, \\ DMedSc, ${ }^{4}$ Mikael Sallinen, PhD, ${ }^{3,5}$ Kari Tokola, MSc, ${ }^{1,6}$ Mikael Fogelholm, DSc ${ }^{7}$
}

Puhkala J. Kukkonen-Harjula K, Mansikkamäki K, Aittasalo M, Hublin C, Kärmeniemi P, Olkkonen S, Partinen M, Sallinen M, Tokola K, Fogelholm M. Lifestyle counseling to reduce body weight and cardiometabolic risk factors among truck and bus drivers - a randomized controlled trial. Scand J Work Environ Health. 2015;41(1):54-64 doi:10.5271/sjweh.3463

\begin{abstract}
Objectives We conducted a randomized trial among overweight long-distance drivers to study the effects of structured lifestyle counseling on body weight and cardiometabolic risk factors.

Methods Men with waist circumference $>100 \mathrm{~cm}$ were randomized into a lifestyle counseling (LIFE, N=55) and a reference $(\mathrm{REF}, \mathrm{N}=58$ ) group. The LIFE group participated in monthly counseling on nutrition, physical activity, and sleep for 12 months aiming at 10\% weight loss. After 12 months, the REF group participated in 3-month counseling. Assessments took place at 0, 12, and 24 months. Between-group differences in changes were analyzed by generalized linear modeling. Metabolic risk ( $\mathrm{Z}$ score) was calculated from components of metabolic syndrome.

Results The mean body weight change after 12 months was $-3.4 \mathrm{~kg}$ in LIFE ( $\mathrm{N}=47)$ and $0.7 \mathrm{~kg}$ in $\mathrm{REF}(\mathrm{N}=48)$ [net difference $-4.0 \mathrm{~kg}, 95 \%$ confidence interval $(95 \% \mathrm{CI})-1.9--6.2$ ]. Six men in LIFE reduced body weight by $\geq 10 \%$. Changes in waist circumference were $-4.7 \mathrm{~cm}$ in LIFE and $-0.1 \mathrm{~cm}$ in REF (net $-4.7 \mathrm{~cm}, 95 \% \mathrm{CI}-6.6-$ -2.7). Metabolic risk decreased more in the LIFE than REF group (net -1.2 points, $95 \% \mathrm{CI}-0.6--2.0$ ). After 24 months follow-up, there were no between-group differences in changes in body weight (net $-0.5 \mathrm{~kg}, 95 \% \mathrm{CI}$ $-3.8-2.9$ ) or metabolic risk score (net 0.1 points; $95 \%$ CI $-0.8-1.0$ ) compared to baseline.
\end{abstract}

Conclusions Weight reduction and decreases in cardiometabolic risk factors were clinically meaningful after 12 months of counseling.

Key terms exercise; metabolic syndrome; MeS; nutrition; obesity; professional driver; walking; weight loss.

The work of long-distance truck and bus drivers typically consists of long and irregular hours or shift work, and lengthy sitting periods $(1,2)$. Busy schedules and lack of healthy food choices and opportunity for exercise while on the road may predispose drivers to an unhealthy lifestyle $(1,3,4)$. Irregular eating and snacking is common (3). Shift work and night shifts in general have been found to be associated with unhealthy eating habits as well as with weight gain (5-7). Prolonged sitting at work is an independent risk factor for athero- sclerosis and diabetes (8). There are also socioeconomic aspects behind drivers' lifestyles. Truck drivers are often sedentary in their leisure time, and they consume less fruit and vegetables and more sausages and milk fat than recommended (9-11). Most professional drivers are males, who tend to be sedentary more often and have poorer diet than women (12).

Long and irregular work hours predispose drivers to sleep deprivation, which is associated with obesity and other cardiometabolic risk factors $(13,14)$, as well as

1 UKK Institute for Health Promotion Research, Tampere, Finland.

2 Tampere University of Applied Sciences, Tampere, Finland.

3 Finnish Institute of Occupational Health, Helsinki and Lappeenranta, Finland.

4 Helsinki Sleep Clinic, Vitalmed Research Centre, Helsinki, Finland.

5 Agora Center, University of Jyväskylä, Jyväskylä, Finland.

6 School of Health Sciences, University of Tampere, Tampere, Finland.

7 Department of Food and Environmental Sciences, University of Helsinki, Helsinki, Finland. 
increased risk of road accidents $(15,16)$. Based on studies about actual sleeping time, truck drivers often suffer from sleep deprivation up to several hours per 24 hours compared to recommendations of 7-8 hours of sleeping time (17-19). Among professional drivers, obesity is associated with increased risk of being fatigued and involved in road traffic accident $(15,20)$. Among the underlying pathological processes, the central ones are breathing disorders during sleep that are induced by obesity (21).

Obesity is one of the most important health risk factors among professional drivers $(15,22,23)$. Worldwide around $57 \%-87 \%$ of truck and bus drivers are overweight or obese (23-26), and obesity comorbidities such as hypertension, dyslipidemia, and type 2 diabetes are common to this profession (23). Overweight and obese truck drivers have substantially greater direct medical costs when compared to drivers of normal weight (23). In a Danish study, hospitalization for obesity or diabetes was more common among truck drivers than among other working populations (22). Additionally, in Europe. obese persons have a $50 \%$ higher risk for disability pension when compared to persons who are not overweight (27).

Although unhealthy lifestyle and cardiometabolic risk factors are frequent among professional drivers (22, 28-30), few health education interventions have been targeted at this group. To our knowledge, the only previous randomized trial to prevent obesity was conducted among 1061 overweight transit workers, mostly metropolitan bus drivers, lasting 18 months (25). Participants in the experimental group were encouraged to make healthy food choices and increase physical activity by being offered sports activities and healthy and affordable options in snack vending machines. Dietary habits improved but the modest body weight reduction did not differ from the control group. A Chinese randomized intervention delivered diabetes-related information by mobile messages, which led to a decreased risk of developing diabetes among 104 professional drivers with pre-diabetes symptoms (31).

According to previous studies, the most important factor preventing professional drivers from adopting a lifestyle change is irregular working schedule $(3,25$, 32 ), which disrupt healthy eating habits, as well as sleep, exercise and social life (1). In a US study, almost half of 542 motor freight workers, most of whom were truck drivers, reported that they would not have time to eat right because of their work, although $86 \%$ thought it would be especially important to eat right (11). In addition, there are few intervention studies focusing on male workers with the same socioeconomic status as drivers, such as construction and manufacturing industrial workers, with or without shift work. These intervention studies have resulted in clinically meaningful decreases in body weight and cardiovascular risk factors $(33,34)$. However, males are often less likely than females to participate in lifestyle counseling to improve lifestyle habits, especially to decrease overweight (35-37).

Our primary aim was to study the effects of individual lifestyle counseling (nutrition, physical activity, and sleep) for 12 months on weight reduction and prevalence of cardiometabolic risk factors (especially metabolic syndrome: MeS) among abdominally obese male truck and bus drivers. A secondary aim was to study weight maintenance during a subsequent 12-month follow up (at 24 months).

\section{Methods}

\section{Recruitment and randomization of participants}

Inclusion criteria included: (i) 30-62-year-old male truck or bus driver, (ii) waist circumference $\geq 100 \mathrm{~cm}$, (iii) irregular working schedules in long-distance service, (iv) absence of sleep apnea diagnosis or medication for diabetes, and (v) little physical activity during leisure ( $\leq 2$ times weekly for 30 minutes per session). Voluntary participants were recruited by advertisement in service stations, workplaces, and newspapers and through labor unions. After 1.5 years of recruitment, 209 drivers signed up for the trial (figure 1).

Of these, 113 drivers were eligible for the study and randomized into a lifestyle counseling (LIFE) and a wait-list reference (REF) group. Randomization was performed by a statistician not involved in the study. It was done separately for truck and bus drivers using computerized random numbers in blocks $(\mathrm{N}=4$, with random variation in the block size). The statistician prepared sealed opaque envelopes containing information on the randomization group, and the research secretary delivered the envelopes in consecutive order to eligible participants after a written informed consent was obtained from the participants. Pirkanmaa University Hospital District Ethics Committee approved the study. The research was conducted in accordance with the Declaration of Helsinki (2000). The ultimate aim of the trial, to improve alertness at work and improve sleep through weight loss, will be reported separately.

\section{Lifestyle counseling}

The participants in the LIFE group participated in structured monthly lifestyle counseling for 12 months focusing on diet but including also counseling on physical activity and sleep. The contents of the session-specific counseling are described in table 1. Counseling consisted of six individual face-to-face contacts (allocated time 60 minutes) and seven telephone contacts (30 minutes) with trained counselors (two nutritionists and one physiotherapist). The counselors traveled to the participants for the 
Table 1. The contents of session-specific counseling in the lifestyle counseling group. [F=face-to-face; T=telephone; $P A=$ physical activity]

\begin{tabular}{|c|c|}
\hline \multicolumn{2}{|c|}{$\begin{array}{l}\text { Session number } \\
\text { (months from } \\
\text { baseline) } \\
\text { type of contact }\end{array}$} \\
\hline $1^{\text {st }}(0) \mathrm{F}$ & $\begin{array}{l}\text { General: overview of counseling, working methods } \\
\text { Diet: checklist for eating habits, based on food diary, meal } \\
\text { frequency (establishing goals for next } 4 \text { weeks) } \\
\text { PA: instructions to measure average daily step count with } \\
\text { a pedometer }\end{array}$ \\
\hline $2^{\text {nd }}(1) F$ & $\begin{array}{l}\text { Diet: meal frequency (compliance, revision of goals); plate } \\
\text { model (establishing goals) } \\
\text { PA: current PA and step count results; PA recommenda- } \\
\text { tions; establishing the first goal }\end{array}$ \\
\hline $3^{\text {rd }}(2) T$ & $\begin{array}{l}\text { Diet: meal frequency and plate model (compliance, revi- } \\
\text { sion of goals); food groups and their quality (establishing } \\
\text { goals) } \\
\text { PA: adverse effects, compliance, revision of goals and } \\
\text { modes, stretching exercises }\end{array}$ \\
\hline $4^{\text {th }}(3) \mathrm{F}$ & $\begin{array}{l}\text { Diet: meal frequency, plate model and food quality (compli- } \\
\text { ance, revision and establishing goals) } \\
\text { PA: adverse effects, compliance, revision of goals and } \\
\text { modes } \\
\text { Sleep: Sleep hygiene (establishing goals) }\end{array}$ \\
\hline $5^{\text {th }}(4) T$ & $\begin{array}{l}\text { Diet: as session } 4 \\
\text { PA: as session } 4 \\
\text { Sleep: Sleep hygiene (compliance, revision of goals) }\end{array}$ \\
\hline $6^{\text {th }}(5) T$ & $\begin{array}{l}\text { Diet: as session } 4 \\
\text { PA: as session } 4 \\
\text { Sleep: Sleep hygiene (compliance, revision of goals), alert- } \\
\text { ness (establishing goals) }\end{array}$ \\
\hline $7^{\text {th }}(6) \mathrm{F}$ & $\begin{array}{l}\text { Diet: as session } 4 \\
\text { PA: as session } 4 \\
\text { Sleep: as session } 6\end{array}$ \\
\hline $\begin{array}{l}8-12^{\text {th }}(7-11) \\
4 \mathrm{~T}, 1 \mathrm{~F}\end{array}$ & $\begin{array}{l}\text { Diet: as session } 4 \\
\text { PA: as session } 4 \\
\text { Sleep: as session } 6\end{array}$ \\
\hline $13^{\text {th }}(12) \mathrm{F}$ & $\begin{array}{l}\text { Diet: check list for eating habits, compliance with goals } \\
\text { during the year, maintenance, how to continue? (goals) } \\
\text { PA: adverse effects, maintenance } \\
\text { Sleep: compliance with goals during the year; how to } \\
\text { continue? }\end{array}$ \\
\hline
\end{tabular}

face-to-face meetings. After 12 months, the REF group participated in a shorter 3-month counseling protocol including two face-to-face contacts (at 12 and 15 months after baseline) and three telephone contacts (3, 6, and 9 weeks after 12 months). Counseling was based on the same elements as those used in the LIFE group but in a shortened version. The second year was a follow-up phase (12 months for LIFE, 9 months for REF).

LIFE group counseling aimed at $10 \%$ body weight reduction after 12 months. The ultimate dietary targets were to improve meal frequency, increase the consumption of fruit and vegetables (with the help of a "plate model": half of the portion is filled with vegetables, one fourth with potatoes, rice or pasta, and one fourth with meat or fish), improve fat quality, and reduce low-fiber, rapidly absorbed carbohydrates (38) (table 1). The ultimate goal of physical activity counseling was to add 4000 steps - approximating 30 minutes of moderate-intensity walking (39) - to the daily baseline on five self-selected days of the week. The goal was approached progressively with the help of a pedometer (Omron Walking Style II, HJ-113-E-03-10/05, Omron Healthcare, Kyoto, Japan) by setting smaller goals in a sequence of 2000 steps, which has previously been shown to be achievable $(40,41)$. The sleep target was $\geq 6$ hours of sleep per 24 hours.

The Health Action Process Approach (42-44) was used as a context to formulate the procedure and contents of the counseling sessions (table 1). The counselors used a manual developed by the research group to follow the intended procedure and content of each counseling session but were also free to emphasize topics most relevant to the participant. At each session, individual goals for diet, physical activity and sleep were set based on participant's preferences, abilities, and experiences. The participants had a log book of their own to monitor the daily accomplishment of their dietary, physical activity and sleep goals. Feasibility and results of counseling on living habits will be reported separately.

\section{Outcome measurements}

Assessments took place at baseline, and at 12- and 24-month follow-up. Body weight was measured by a precision scale (F150S-D2, Sartorius, Goettingen, Germany). Waist circumference was measured three times: (midway between the lowest rib and the iliac crest) and the mean value was used. Dual-energy X-ray absorptiometry (DXA, Lunar Prodigy Advance, GE Lunar, Madison, WI, USA) was used to measure fat and fat-free mass. Blood pressure was measured in duplicate in the morning and afternoon, and the mean value was used. The participants answered a questionnaire on health status and working conditions. At each counseling meeting, weight (Omron HBF-500-E, Omron Healthcare, Kioto, Japan) and waist circumference were measured.

Blood samples were taken for glucose, cholesterol, high-density lipoprotein (HDL) cholesterol and triglyceride analyses after a 12-hour fast. Venous blood was drawn into citric acid/fluoride and ethylenediaminetetraacetic acid (EDTA) tubes. Plasma glucose concentrations were measured fresh, and plasma samples for lipid analyses were stored frozen at $-80^{\circ} \mathrm{C}$ until analyzed. Glucose, total cholesterol, HDL cholesterol and triglyceride concentrations were determined in enzymatic assays in duplicate (Roche Cobas Mira Plus analyzer; Roche Diagnostic Systems, Basel, Switzerland). Lowdensity lipoprotein (LDL) cholesterol was calculated by Friedewald formula if triglyceride concentration was $<4.51 \mathrm{mmol} / \mathrm{l}$. MeS was diagnosed according to the International Diabetes Federation (IDF) guidelines (45), based on five components: waist circumference, blood pressure, fasting glucose, HDL cholesterol and triglyc- 


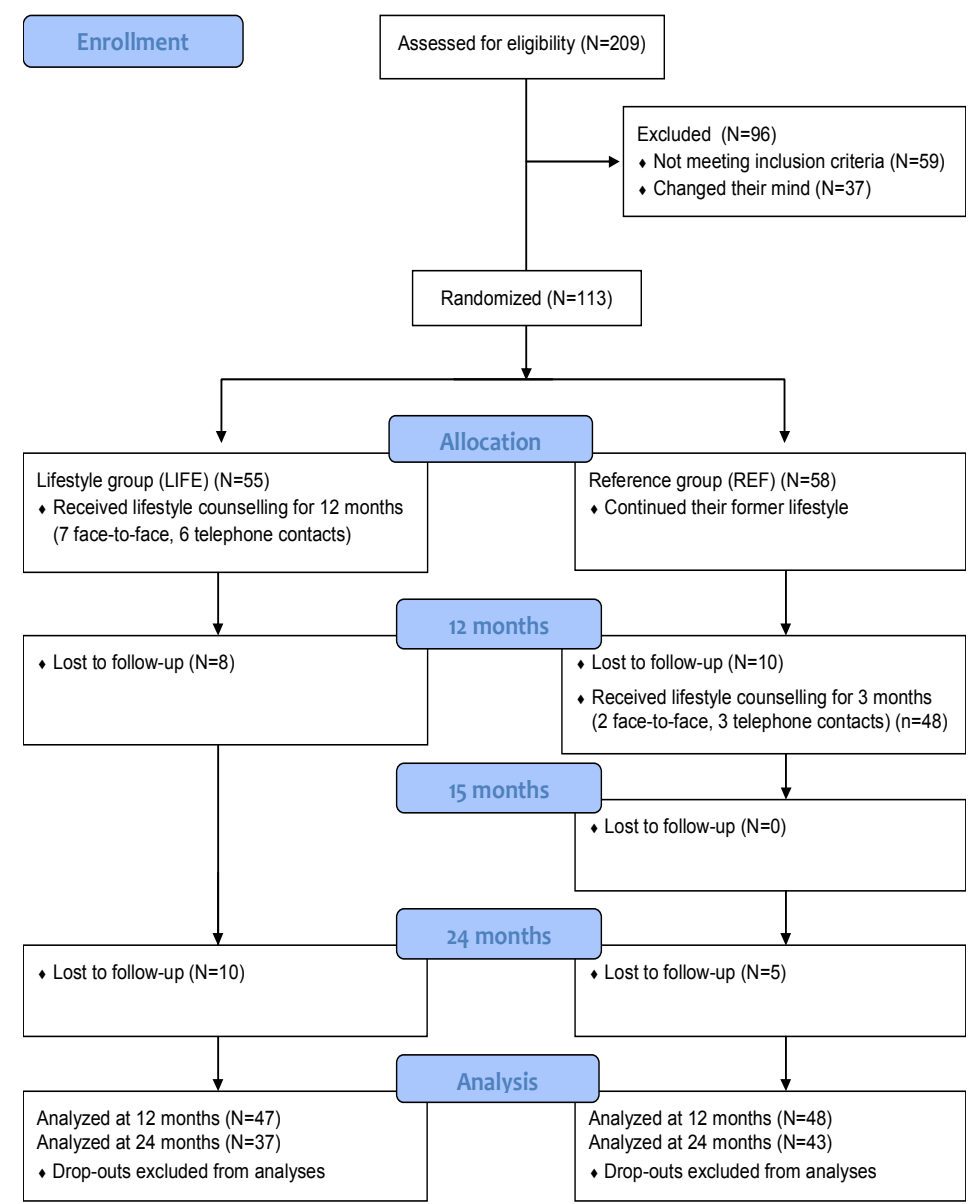

Figure 1. Flow diagram of the study. The lifestyle counseling (LIFE) group participated in 12 months of counseling starting from baseline and the reference (REF) group participated in three months of counseling starting at 12 months. Assessments took place at baseline, 12, and 24 months from baseline. erides. Of these, three pathological values are needed for the diagnosis. Impaired fasting glucose (IFG: fasting plasma glucose $\geq 5.6 \mathrm{mmol} / \mathrm{l}$ ) was diagnosed according to the IDF guidelines.

\section{Power calculation}

Statistical power calculations were based on the assumption that $25 \%$ of LIFE participants and $5 \%$ of REF participants had reached the target of losing $10 \%$ of their initial body weight after 12 months. Using Fisher's exact test, it was calculated that with 59 LIFE participants and REF 59 participants, there was a $84 \%$ probability (power $84 \%$, type II error $16 \%$ ) to detect a significant difference between the groups at a two-sided 0.05 significance level (Alfa $=0.05$, type I error). The drop-out rate was expected to be $15 \%$, and therefore we aimed to recruit 140 persons.

\section{Statistical analysis}

Linear regression models adjusted by baseline were used to analyze statistical differences in changes between the groups in body composition and cardiometabolic risk factors in assessments after 12 and 24 months. Fisher's exact test was used to analyze differences in the proportions of successful weight losers ( $\geq 10 \%$ of body weight after 12 months) between the LIFE and REF groups. Generalized estimating equations with binary logistic regression using age, time and quadratic time as covariates were used to estimate between-group differences in proportions of participants with $\mathrm{MeS}$ or IFG in time (longitudinal data, three measurement points). Interaction of group and time, and group and quadratic time were added to the model to assess linear and non-linear between-group differences in time.

To further evaluate the metabolic risk and its changes, we calculated $\mathrm{Z}$ scores for MeS components (waist circumference, blood pressure, glucose, HDL cholesterol and triglycerides). Each component was log-transformed and standardized. The Z score of HDL cholesterol was multiplied by -1 to indicate higher metabolic risk with increasing value. The $\mathrm{Z}$ score of blood pressure was calculated as the average of systolic and diastolic blood pressure $\mathrm{Z}$ scores. $\mathrm{Z}$ scores from the five components were summed up as the metabolic risk score (46). The change in the metabolic risk Z score between 
the groups was modeled by linear regression using baseline value as a covariate. All results were considered to be statistically significant if $\mathrm{P}<0.05$ or if $95 \%$ confidence intervals $(95 \% \mathrm{CI})$ did not cross zero. All analyses were performed with SPSS software, version 21.0 (IBM Corp, Armonk, NY, USA).

\section{Results}

Eighty-three (74\%) participants were truck drivers and thirty $(26 \%)$ were bus drivers. The mean duration of truck or bus driving experience was 24.0 [standard deviation (SD) 14.9] years. Twenty-four (21\%) participants used cigarettes or other tobacco products daily. Age, body composition, and components of $\mathrm{MeS}$ at baseline are presented in table 2 . One fourth $(25 \%, \mathrm{~N}=28)$ had a body mass index (BMI) of $<30 \mathrm{~kg} / \mathrm{m}^{2}$, about half $(47 \%$, $\mathrm{N}=53)$ of $30-34.9 \mathrm{~kg} / \mathrm{m}^{2}$, and about one fourth $(28 \%$, $\mathrm{N}=32$ ) of $\geq 35 \mathrm{~kg} / \mathrm{m}^{2}$. Twenty-five (22\%) participants reported use of medication for hypertension, twelve (11\%) for dyslipidemia, and one (1\%) for type-2 diabetes. One participant had coronary heart disease. More than two out of three $(71 \%, \mathrm{~N}=80)$ had MeS at baseline.

Of the 113 randomized participants, 95 (84\%) participated in 12-month and $80(71 \%)$ in 24-month measurements (figure 1). One LIFE participant died before the 24-month measurements (the cerebrovascular cause of death was not related to the intervention). The mean participation of LIFE $(\mathrm{N}=47)$ in allocated monthly counseling sessions was 10.8 sessions (out of 11 allocated sessions) between months 1-11, resulting in participation rate of $98 \%$. The corresponding results in the REF group $(\mathrm{N}=48$ ) between months $12-15$ were 3.97 sessions (out of 4 allocated sessions) and a $99 \%$ participation rate.

The mean body weight change (versus baseline) after 12 months was $-3.4(\mathrm{P}=0.001$, range $-26.1-9.9) \mathrm{kg}$ in LIFE $(\mathrm{N}=47)$ and $0.7(\mathrm{P}=0.214$, range $-9.5-12.5) \mathrm{kg}$ in REF $(\mathrm{N}=48)$, the net difference being $-4.0 \mathrm{~kg}(95 \% \mathrm{CI}$ -6.2- -1.9) (table 3). The differences of changes in waist circumference and body fat were statistically significant in favor of the LIFE group after 12 months. The change in lean body mass did not differ between the LIFE and REF group (net difference $-0.6 \mathrm{~kg}, 95 \% \mathrm{CI}-1.4--0.2$ ). Six $(13 \%)$ LIFE participants $(\mathrm{N}=47)$ reduced body weight by $\geq 10 \%$, and another six (13\%) lost 5-9.9\% of initial body weight. In the REF group $(\mathrm{N}=48)$, the corresponding numbers were zero and three $(6 \%)(\mathrm{P}=0.01$ and $\mathrm{P}=0.3$ between the groups). Seven (15\%) and fifteen (31\%) LIFE and REF participants gained body weight by $\geq 2 \%$, respectively ( $\mathrm{P}=0.09$ between the groups).

At baseline, $44(80 \%)$ of 55 LIFE participants and $36(62 \%)$ of 58 REF participants had MeS. After 12 months, the prevalence had decreased to $62 \%$ (29 of
47 LIFE) and to $60 \%$ (29 of 48 REF). The difference in the change of proportions between the groups was not statistically significant $(\mathrm{P}=0.34$, logistic regression analysis). Metabolic risk $\mathrm{Z}$ score reduced more in the LIFE compared REF group (net difference -1.2 points, 95\% CI -0.6- -2.0, linear regression) (figure 2).

At baseline, $44(80 \%)$ of 55 LIFE participants and $42(72 \%)$ of 58 REF participants had IFG. After 12 months, the prevalence had decreased to 64\% (30 of 47 LIFE) and increased to $77 \%$ (37 of $48 \mathrm{REF)} \mathrm{(P=0.012}$ between the groups). Among all LIFE participants, the mean change in glucose concentration after 12 months was $-0.15 \mathrm{mmol} / 1$ (SD 0.43) and $0.01 \mathrm{mmol} / 1$ (SD 0.43) among REF participants, the net difference being -0.15 $\mathrm{mmol} / 1$ (95\% CI -0.33- -0.02). After 12 months, the mean concentration of LIFE group HDL cholesterol increased by $0.02 \mathrm{mmol} / \mathrm{l}$ (SD 0.11) and decreased by $0.03 \mathrm{mmol} / 1(0.26)$ in the REF group (net difference $0.06 \mathrm{mmol} / 1,95 \%$ CI 0.02-0.18). Also diastolic blood pressure tended to improve more in the LIFE than REF, group the net difference being $-2.7 \mathrm{mmHg}(95 \% \mathrm{CI}$ $-5.2-0.1)$ after 12 months. There were no statistically significant differences in the changes in total and LDL cholesterol, triglycerides, and systolic blood pressure between the groups after 12 months.

The waitlist REF group received 3 months of counseling, starting at 12 months from baseline. After 3 months, they lost $4.0 \mathrm{~kg}$ (SD 4.2) of body weight and $4.1 \mathrm{~cm}$ (SD 4.1) of waist circumference when compared to the 12 -month assessment. Of 48 participants, $3(6 \%)$ reduced body weight by $\geq 10 \%$ and $13(28 \%)$ reduced body weight by $5-9.9 \%$ after the counseling.

After 24 months, there were no statistically significant differences in the changes of body weight, waist circumference and fat mass between the LIFE and REF group when compared to baseline (table 2). About onetenth had reduced body weight by $\geq 10 \%$ from baseline, ie, four (11\%) LIFE participants and three (7\%) REF participants. The corresponding numbers with body weight loss of $5-9.9 \%$ were nine $(24 \%)$ in the LIFE and $13(30 \%)$ in the REF group. There were $11(30 \%)$ participants in LIFE and $10(23 \%)$ in REF who gained body weight by $\geq 2 \%$.

After 24 months, the prevalence of $\mathrm{MeS}$ had decreased to $60 \%$ (22 of 37 LIFE) and 51\% (22 of 43 REF). The between-group difference in the prevalence curves during 24 months (assessment at 0, 12, and 24 months from baseline) was not statistically significant (interaction between the group and quadratic time $\mathrm{P}=0.11$ ). Neither was there a difference in change in metabolic risk $\mathrm{Z}$ scores between the groups after 24 months compared to baseline (net difference $0.1,95 \%$ CI -0.8-1.0).

According to drop-out analysis, there were no differences in baseline characteristics (body composition, 
Table 2. Characteristics of participants $(\mathrm{N}=113)$ at baseline in the lifestyle counseling (LIFE, $N=55)$ group and reference (REF, $N=58)$ group. [SD=standard deviation; $\mathrm{MD}=$ median; $\mathrm{Q}=$ quartile; $\mathrm{BMI}=$ body mass index; HDL=high-density lipoprotein; LDL=low-density lipoprotein]

\begin{tabular}{|c|c|c|c|c|c|c|c|c|c|c|}
\hline & \multicolumn{5}{|c|}{ LIFE $(\mathrm{N}=55)$} & \multicolumn{5}{|c|}{$\mathrm{REF}(\mathrm{N}=58)$} \\
\hline & Mean & $\mathrm{SD}$ & $\mathrm{MD}$ & Q1 & Q3 & Mean & SD & MD & Q1 & Q3 \\
\hline Age (years) & 47.6 & 7.9 & & & & 46.5 & 8.6 & & & \\
\hline Waist circumference (cm) & 113.8 & 9.5 & & & & 114.9 & 10.3 & & & \\
\hline Body weight $(\mathrm{kg})$ & 105.8 & 16.3 & & & & 106.7 & 16.4 & & & \\
\hline $\mathrm{BMI}$ a $\left(\mathrm{kg} / \mathrm{m}^{2}\right)$ & 32.9 & 4.3 & & & & 33.1 & 4.7 & & & \\
\hline Fat mass (kg) & 37.1 & 8.9 & & & & 38.0 & 9.0 & & & \\
\hline Systolic pressure (mmHg) & 130.5 & 13.5 & & & & 127.8 & 11.3 & & & \\
\hline Diastolic pressure $(\mathrm{mmHg})$ & 84.8 & 9.3 & & & & 82.5 & 8.3 & & & \\
\hline Glucose (mmol/l) & 6.0 & 0.6 & & & & 6.0 & 0.6 & & & \\
\hline Total cholesterol (mmol/l) & 5.47 & 0.94 & & & & 5.56 & 1.01 & & & \\
\hline HDL cholesterol (mmol/l) & 1.27 & 0.30 & & & & 1.25 & 0.26 & & & \\
\hline LDL cholesterol (mmol/l) a & 3.39 & 0.87 & & & & 3.58 & 0.90 & & & \\
\hline Triglycerides $(\mathrm{mmol} / \mathrm{l})$ & & & 1.67 & 1.11 & 2.08 & & & 1.41 & 1.11 & 2.11 \\
\hline Metabolic risk Z score ${ }^{b}$ & 0.16 & 2.74 & & & & -0.15 & 2.84 & & & \\
\hline
\end{tabular}

a $\mathrm{N}=54$ (LIFE) and $\mathrm{N}=57$ (REF).

b The sum of five components (waist circumference, blood pressure, glucose, HDL cholesterol and triglycerides) of metabolic syndrome.

Table 3. Body weight, waist circumference and fat mass at baseline $(\mathrm{N}=113)$ and their changes in assessments after 12 and 24 months versus baseline and net differences of the changes between the lifestyle (LIFE) and reference (REF) group. [SD=standard deviation; $\mathrm{N}=$ number of participants; $95 \% \mathrm{Cl}=95 \%$ confidence interval]

\begin{tabular}{|c|c|c|c|c|c|c|c|c|c|c|}
\hline & \multirow{2}{*}{\multicolumn{2}{|c|}{$\begin{array}{c}\text { Baseline } \\
\text { All }(\mathrm{N}=113)\end{array}$}} & \multicolumn{8}{|c|}{ Change versus baseline } \\
\hline & & & \multicolumn{3}{|c|}{ LIFE } & \multicolumn{3}{|c|}{ REF } & \multirow[b]{2}{*}{$\begin{array}{c}\text { Net } \\
\text { difference a }\end{array}$} & \multirow[b]{2}{*}{$95 \% \mathrm{Cl}$} \\
\hline & Mean & SD & Mean & SD & $\mathrm{N}$ & Mean & $\mathrm{SD}$ & $\mathrm{N}$ & & \\
\hline Weight (kg) & 106.3 & 16.3 & & & & & & & & \\
\hline 12 months & & & -3.4 & 6.6 & 47 & 0.7 & 3.9 & 48 & -4.0 & $-6.2--1.9$ \\
\hline 24 months & & & -3.1 & 9.0 & 37 & -2.5 & 5.9 & 43 & -0.5 & $-3.8-2.9$ \\
\hline Waist (cm) & 114.4 & 9.9 & & & & & & & & \\
\hline 12 months & & & -4.7 & 5.8 & 47 & -0.1 & 3.6 & 48 & -4.7 & $-6.6--2.7$ \\
\hline 24 months & & & -4.5 & 7.5 & 37 & -4.4 & 5.5 & 43 & -0.2 & $-3.1-2.8$ \\
\hline Fat mass (kg) & 37.5 & 8.9 & & & & & & & & \\
\hline 12 months & & & -2.6 & 5.1 & 46 & 0.6 & 3.4 & 48 & -3.1 & $-4.9--1.4$ \\
\hline 24 months & & & -2.2 & 6.9 & 36 & -2.3 & 4.6 & 43 & 0.2 & $-2.4-2.8$ \\
\hline
\end{tabular}

a Baseline value as a covariate.

components of $\mathrm{MeS}$ or smoking) between completers and non-completers after 12 months $(\mathrm{N}=95$ versus $\mathrm{N}=18)$ or 24 months $(\mathrm{N}=80$ versus $\mathrm{N}=33$ ). Neither were there differences after 12 months between completers and noncompleters after 24 months $(\mathrm{N}=80$ versus $\mathrm{N}=33)$.

\section{Discussion}

After 12 months of counseling, the mean body weight loss was $3.4 \mathrm{~kg}$ in the LIFE group and the net difference of body weight change was $4.0 \mathrm{~kg}$ favoring LIFE participants. The results are meaningful from a clinical and public health perspective. Thirteen percent in the LIFE and none in the REF group managed to reduce $10 \%$ of initial body weight. There was no difference between the groups in the change in the prevalence of MeS, but the metabolic risk $\mathrm{Z}$ score decreased more in the LIFE than
REF group after 12 months. Waist circumference and HDL cholesterol improved more and the prevalence of IFG decreased more in the LIFE than REF group after 12 months. At the end of the study, after three months of counseling (months 12-15), REF participants had caught up with the weight loss that LIFE had achieved during 12 months. Thus there were no differences in body composition and metabolic risk factors between the groups after 24 months.

Recruitment of overweight long-distance drivers all over Finland was challenging and took 15 months. This was probably mostly due to their long and irregular working hours and because counseling sessions and measurements were implemented during participants' leisure time. Thus we suppose that the most motivated and health conscious men participated. This is also reflected by the fact that only $21 \%$ of the participants were smokers, while the prevalence of regular smoking is around 27\% among Finnish men at the same educa- 


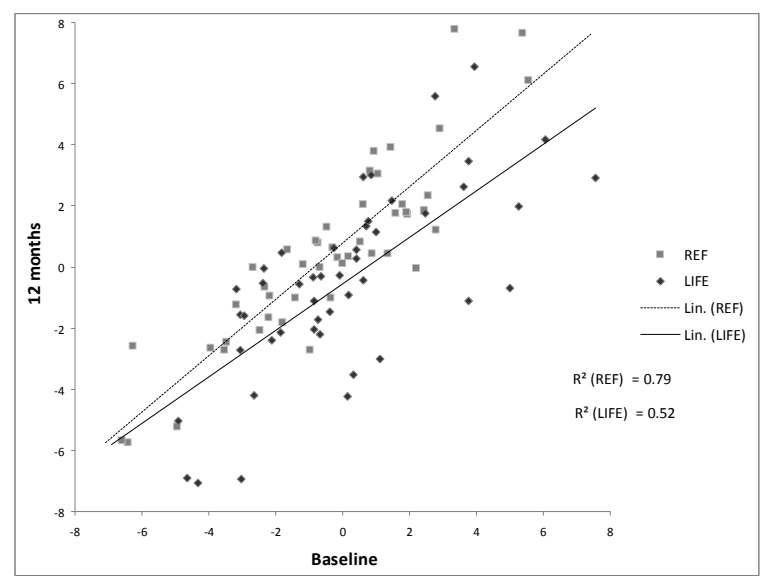

Figure 2. Linear trend and $R^{2}$ of metabolic risk $Z$ score of the lifestyle counseling (LIFE, $N=47$ ) and the reference (REF, $N=48$ ) group between baseline and 12 months. [Lin =linear regression]

tional level (47). Internationally, smoking is more common among professional drivers than in other working populations $(1,9,48)$.

We aimed at a $10 \%$ loss of initial body weight in $\geq 25 \%$ of the LIFE participants after 12 months. Weight loss of at least $5-10 \%$ has been found to be related to reduction in cardiovascular risk factors associated with obesity (49-51). In our study, the proportion of the LIFE participants to actually reach the $10 \%$ weight loss goal was around half of our assumption (13\%). In the REF group, we had assumed $5 \%$ of the participants would reach the goal, but none succeeded. In lifestyle counseling interventions the proportion of participants reducing $\geq 10 \%$ of body weight is rarely reported, though this is a common goal in obesity treatment guidelines (51). However, when compared to previous lifestyle counseling interventions aiming at weight reduction, our result after 12 months (net effect $-4.0 \mathrm{~kg}$ ) is in the same magnitude and clinically relevant $(52,53)$.

According to meta-analyses on treatment of overweight and obese persons, the mean body weight loss in lifestyle interventions varied between 2.3-3.5 kilograms at follow-up for $1-2$ years $(52,53)$. Previous health education interventions have achieved slight to moderate changes in drivers' health behavior and body weight $(25,32,54,55)$, and only one of them has been a randomized intervention (25). Previous weight reduction studies concentrating only on males or shift workers are heterogenic and few. A randomized 6-month Dutch lifestyle counseling intervention resulted in a $-2.2 \mathrm{~kg}$ (95\% CI -3.1- -1.3) net difference at one year among 372 overweight male construction workers (33). Another randomized intervention by phone and email in a Dutch overweight working population ( $\mathrm{N}=1386$, of whom $67 \%$ were males) lead to a net weight loss of $1.5 \mathrm{~kg}(95 \% \mathrm{CI}$ $-2.2--0.8)$ (by phone) and $0.6 \mathrm{~kg}(95 \% \mathrm{CI}-1.3--0.01)$ (by email) compared to control group after six months of lifestyle counseling (56). In an Australian randomized study, a three-month workplace-based weight loss program among 110 overweight male shift workers, led to a net difference of $-4.4 \mathrm{~kg}$ (95\% CI -2.6- -6.1) (34). Overall, in addition to more intensive and expensive individual counseling, work-site interventions (with different methods like group classes, leaflets, poster displays, work-shops, improved cafeteria food choices, and community events) have demonstrated promising results in obesity prevention and reducing cardiovascular disease risk $(57,58)$. However, workplace-bound approaches are not applicable to long-distance drivers.

The body weight regain in the LIFE group from 12 to 24 months was moderate (mean $0.5 \mathrm{~kg}$, SD $4.8 \mathrm{~kg}$ ). According to systematic reviews, about $50 \%$ of weight loss is maintained after one-year follow-up $(59,60)$. In a Finnish weight maintenance study among abdominally obese men, $37 \%$ of achieved body weight loss was maintained for two years after weight reduction by very-low-energy diet followed by exercise training (61).

The body weight decrease of $3.4 \mathrm{~kg}$ among LIFE participants after 12 months in the present study did not lead to a clear reduction in the prevalence of MeS. However, in the metabolic risk $\mathrm{Z}$ score the mean decrease of 1.2 points (95\% CI - $0.6--2.0)$ was significant. Also fasting glucose and HDL cholesterol improved. According to several studies (62-64) it seems that even a modest body weight reduction (3.5-4.2 $\mathrm{kg}$ in 1-2 years) with the aid of diet and exercise is enough for reduction in cardiometabolic risk factors like insulin resistance, impaired glucose tolerance, dyslipidemia, and hypertension. The results of the present study are in line with these studies.

The present study shows that weight reduction with some improvement in cardiometabolic risk factors among long-distance truck and bus drivers is possible through lifestyle counseling, despite challenging working conditions. In addition to the weight loss achieved, an interesting finding was that the shorter three months of counseling in the REF group led to an almost equal body weight loss compared to the more intensive 12 months of counseling in the LIFE group. This may imply that in the short run, lifestyle changes are also achievable with less intensive counseling, which might be more applicable in occupational healthcare. Future studies are, however, needed to support this finding, since the effects of shorter counseling on long-term weight maintenance are not known.

Especially working hours, long absences from home, and dependence on road site food and rest services are substantial barriers to a healthy lifestyle of long-distance drivers. To improve the environment, resting and eating locations should serve healthier food, more showering 
facilities and possibilities to engage in exercise and rest. Professional drivers have shown interest in eating in a healthier way if there were options for these at the resting places $(2,11,24)$. In many countries, including those in EU, Northern America, and some parts of Asia, hours-of-service rules are officially set to control the working and resting times of heavy vehicle professional drivers. In spite of that, economic aspects and international competition may lead to unrealistic delivery schedules and rule violations (65). In our study, we had no possibility to affect drivers' working schedules or access to occupational healthcare.

\section{Strengths and limits of the study}

There are several strengths in the present study. First, our study is the first randomized controlled trial on lifestyle counseling in long-distance drivers. The counseling was planned to be intensive and individually tailored as the group was known to be hard to reach and maintain involvement. As long-distance drivers have no stable working place, participation in each counseling meeting was made as easy as possible for the participants as the counselors traveled to them. The counseling was structured and theory-based, which ensured homogeneity among the three counselors. The duration of the study with follow-up was rather long, namely, two years.

The most important limitation of the study is the number of participants, which makes the study underpowered. We lacked 23 participants from the target of 118 at 12 -month measurements, meaning a gap of $19 \%$. As the recruitment was countrywide, the less-than-optimal number of participating volunteers most probably reflects challenging working hours or lack of interest in health issues. However, the participant drop-out (16\% after 12 months and $29 \%$ after 24 months) was rather low compared to other weight loss studies (37). This probably reflects appreciation of free and easy-to-reach counseling sessions and the attention and advice given by health professionals.

\section{Concluding remarks}

Intensive lifestyle counseling on nutrition, physical activity, and sleep was effective in reducing body weight and cardiometabolic risk factors in overweight professional drivers.

\section{Acknowledgements}

This study was supported by the Academy of Finland, the Ministry of Education and Culture, and the Juho Vainio Foundation.
The authors are thankful to Matti Pasanen, MSc, for statistical advice. We also want to thank Tiina Solakivi, $\mathrm{PhD}$, at the University of Tampere who was responsible for the biochemical analyses. Research secretary Taru Helenius took care of all schedules of appointments. Research secretary Tiina Inkovaara participated in recruitment. Biomedical laboratory scientists Ulla Hakala, Ulla Honkanen, Sirke Rasinperä and Leena Aura, and exercise scientist Katriina Ojala, MSc, performed laboratory assessments. Psychologist Heli Järnefelt, MSc, prepared counselling material and a booklet on sleep hygiene. Nutritionist Anna Ojala, MSc, and nurse Johanna Riippi participated in lifestyle counseling.

The authors declare no conflict of interest.

\section{References}

1. Tse JLM, Flin R, Mearns K. Bus driver well-being review: 50 years of research. Transportation Research: Part F. 2006;9(2):89-114.

2. van der Beek AJ. World at work: Truck drivers. Occup Environ Med. 2012 Apr;69(4):291-5. http://dx.doi.org/10.1136/ oemed-2011-100342.

3. Jack FR, Piacentini MG, Schroder MJ. Perception and role of fruit in the workday diets of Scottish lorry drivers. Appetite. 1998 Apr;30(2):139-49. http://dx.doi.org/10.1006/ appe.1997.0115.

4. Gill PE, Wijk K. Case study of a healthy eating intervention for Swedish lorry drivers. Health Educ Res. 2004 Jun;19(3):30615. http://dx.doi.org/10.1093/her/cyg030.

5. Knutsson A. Health disorders of shift workers. Occup Med (Lond). 2003 Mar;53(2):103-8. http://dx.doi.org/10.1093/ occmed/kqg048.

6. Lowden A, Moreno C, Holmback U, Lennernas M, Tucker P. Eating and shift work - effects on habits, metabolism and performance. Scand J Work Environ Health. 2010 Mar;36(2):150-62. http://dx.doi.org/10.5271/sjweh.2898.

7. van Drongelen A, Boot CR, Merkus SL, Smid T, van der Beek AJ. The effects of shift work on body weight change - a systematic review of longitudinal studies. Scand J Work Environ Health. 2011 Jul;37(4):263-75. http://dx.doi. org/10.5271/sjweh.3143.

8. van Uffelen JG, Wong J, Chau JY, van der Ploeg HP, Riphagen I, Gilson ND, et al. Occupational sitting and health risks: A systematic review. Am J Prev Med. 2010 Oct;39(4):379-88. http://dx.doi.org/10.1016/j.amepre.2010.05.024.

9. Hedberg GE, Jacobsson KA, Janlert U, Langendoen S. Risk indicators of ischemic heart disease among male professional drivers in Sweden. Scand J Work Environ Health. 1993 Oct;19(5):326-33. http://dx.doi.org/10.5271/sjweh.1467.

10. Heimendinger J, Feng Z, Emmons K, Stoddard A, Kinne $\mathrm{S}$, Biener L, et al. The working well trial: Baseline dietary and smoking behaviors of employees and related worksite characteristics. The working well research group. Prev 
Med. 1995 Mar;24(2):180-93. http://dx.doi.org/10.1006/ pmed.1995.1032.

11. Nagler EM, Viswanath K, Ebbeling CB, Stoddard AM, Sorensen G. Correlates of fruit and vegetable consumption among construction laborers and motor freight workers. Cancer Causes Control. 2013 Apr;24(4):637-47. http://dx.doi. org/10.1007/s10552-012-9998-6.

12. Garfield CF, Isacco A, Rogers TE. A review of men's health and masculinity. Am J Lifestyle Med. 2008;2(6):474-87. http://dx.doi.org/10.1177/1559827608323213.

13. Cappuccio FP, Cooper D, D’Elia L, Strazzullo P, Miller MA. Sleep duration predicts cardiovascular outcomes: A systematic review and meta-analysis of prospective studies. Eur Heart J. 2011 Jun;32(12):1484-92. http://dx.doi.org/10.1093/ eurheartj/ehr007.

14. Puttonen S, Harma M, Hublin C. Shift work and cardiovascular disease - pathways from circadian stress to morbidity. Scand J Work Environ Health. 2010 Mar;36(2):96-108. http://dx.doi. org/10.5271/sjweh.2894.

15. Wiegand DM, Hanowski RJ, McDonald SE. Commercial drivers' health: A naturalistic study of body mass index, fatigue, and involvement in safety-critical events. Traffic Inj Prev. 2009 Dec;10(6):573-9. http://dx.doi. org/10.1080/15389580903295277.

16. Taylor AH, Dorn L. Stress, fatigue, health, and risk of road traffic accidents among professional drivers: The contribution of physical inactivity. Annu Rev Public Health. 2006;27:371-91. http://dx.doi.org/10.1146/annurev. publhealth.27.021405.102117.

17. Hanowski RJ, Hickman J, Fumero MC, Olson RL, Dingus TA. The sleep of commercial vehicle drivers under the 2003 hoursof-service regulations. Accid Anal Prev. 2007 Nov;39(6):1140 5. http://dx.doi.org/10.1016/j.aap.2007.02.011.

18. Mitler MM, Miller JC, Lipsitz JJ, Walsh JK, Wylie CD. The sleep of long-haul truck drivers. N Engl J Med. 1997 Sep 11;337(11):755-61. http://dx.doi.org/10.1056/ NEJM199709113371106.

19. Marqueze EC, Ulhoa MA, Moreno CR. Irregular working times and metabolic disorders among truck drivers: A review. Work. 2012;41 Suppl 1:3718-25.

20. Anderson JE, Govada M, Steffen TK, Thorne CP, Varvarigou $\mathrm{V}$, Kales $\mathrm{SN}$, et al. Obesity is associated with the future risk of heavy truck crashes among newly recruited commercial drivers. Accid Anal Prev. 2012 Nov;49:378-84. http://dx.doi. org/10.1016/j.aap.2012.02.018.

21. Jordan AS, McSharry DG, Malhotra A. Adult obstructive sleep apnoea. Lancet. 2014 Feb 22;383(9918):736-47. http://dx.doi. org/10.1016/S0140-6736(13)60734-5.

22. Dahl S, Kaerlev L, Jensen A, Tuchsen F, Hannerz H, Nielsen PS, et al. Hospitalization for lifestyle related diseases in long haul drivers compared with other truck drivers and the working population at large. Work. 2009;33(3):345-53.

23. Martin BC, Church TS, Bonnell R, Ben-Joseph R, Borgstadt $\mathrm{T}$. The impact of overweight and obesity on the direct medical costs of truck drivers. J Occup Environ Med. 2009 Feb;51(2):180-4. http://dx.doi.org/10.1097/

\section{JOM.0b013e3181965d6e}

24. Apostolopoulos Y, Sonmez S, Shattell MM, Gonzales C, Fehrenbacher C. Health survey of U.S. long-haul truck drivers: Work environment, physical health, and healthcare access. Work. 2013 Jan 1;46(1):113-23.

25. French SA, Harnack LJ, Hannan PJ, Mitchell NR, Gerlach AF, Toomey TL. Worksite environment intervention to prevent obesity among metropolitan transit workers. Prev Med. 2010 Apr;50(4):180-5. http://dx.doi.org/10.1016/j. ypmed.2010.01.002.

26. Moreno CR, Louzada FM, Teixeira LR, Borges F, LorenziFilho G. Short sleep is associated with obesity among truck drivers. Chronobiol Int. 2006;23(6):1295-303. http://dx.doi. org/10.1080/07420520601089521.

27. Robroek SJ, Reeuwijk KG, Hillier FC, Bambra CL, van Rijn RM, Burdorf A. The contribution of overweight, obesity, and lack of physical activity to exit from paid employment: A meta-analysis. Scand J Work Environ Health. 2013 May 1;39(3):233-40. http://dx.doi.org/10.5271/sjweh.3354.

28. Davila EP, Florez H, Fleming LE, Lee DJ, Goodman E, LeBlanc WG, et al. Prevalence of the metabolic syndrome among U.S. workers. Diabetes Care. 2010 Nov;33(11):2390-5. http://dx.doi.org/10.2337/dc10-0681.

29. Marqueze EC, Ulhoa MA, Moreno CR. Effects of irregularshift work and physical activity on cardiovascular risk factors in truck drivers. Rev Saude Publica. 2013 Jun;47(3):497-505. http://dx.doi.org/10.1590/S0034-8910.2013047004510.

30. Apostolopoulos Y, Shattell MM, Sonmez S, Strack R, Haldeman L, Jones V. Active living in the trucking sector: Environmental barriers and health promotion strategies. J Phys Act Health. 2012 Feb;9(2):259-69.

31. Wong CK, Fung CS, Siu SC, Lo YY, Wong KW, Fong DY, et al. A short message service (SMS) intervention to prevent diabetes in Chinese professional drivers with pre-diabetes: A pilot single-blinded randomized controlled trial. Diabetes Res Clin Pract. 2013 Dec;102(3):158-66. http://dx.doi. org/10.1016/j.diabres.2013.10.002.

32. Emdad R, Belkic K, Theorell T, Cizinsky S. What prevents professional drivers from following physicians' cardiologic advice? Psychother Psychosom. 1998 Jul-Oct;67(4-5):226-40. http://dx.doi.org/10.1159/000012285.

33. Groeneveld IF, Proper KI, van der Beek AJ, van Mechelen W. Sustained body weight reduction by an individual-based lifestyle intervention for workers in the construction industry at risk for cardiovascular disease: Results of a randomized controlled trial. Prev Med. 2010 Sep-Oct;51(3-4):240-6. http://dx.doi.org/10.1016/j.ypmed.2010.07.021.

34. Morgan PJ, Collins CE, Plotnikoff RC, Cook AT, Berthon B, Mitchell S, et al. Efficacy of a workplace-based weight loss program for overweight male shift workers: The workplace POWER (preventing obesity without eating like a rabbit) randomized controlled trial. Prev Med. 2011 May;52(5):31725. http://dx.doi.org/10.1016/j.ypmed.2011.01.031.

35. George ES, Kolt GS, Duncan MJ, Caperchione CM, Mummery WK, Vandelanotte $\mathrm{C}$, et al. A review of the 
effectiveness of physical activity interventions for adult males. Sports Med. 2012 Apr 1;42(4):281-300. http://dx.doi. org/10.2165/11597220-000000000-00000.

36. Pagoto SL, Schneider KL, Oleski JL, Luciani JM, Bodenlos JS, Whited MC. Male inclusion in randomized controlled trials of lifestyle weight loss interventions. Obesity (Silver Spring). 2012 Jun;20(6):1234-9. http://dx.doi.org/10.1038/ oby.2011.140.

37. Young MD, Morgan PJ, Plotnikoff RC, Callister R, Collins CE. Effectiveness of male-only weight loss and weight loss maintenance interventions: A systematic review with metaanalysis. Obes Rev. 2012 May;13(5):393-408. http://dx.doi. org/10.1111/j.1467-789X.2011.00967.x.

38. Becker W, Lyhne N, Pedersen AN, Aro A, Fogelholm M, Phósdottir I, et al. Nordic nutrition recommendations 2004 integrating nutrition and physical activity. Scand J Nutr. 2004 12;48(4):178-87.

39. Welk GJ, Differding JA, Thompson RW, Blair SN, Dziura J, Hart P. The utility of the digi-walker step counter to assess daily physical activity patterns. Med Sci Sports Exerc. 2000 Sep;32(9 Suppl):S481-8. http://dx.doi. org/10.1097/00005768-200009001-00007.

40. Wyatt H, Peters J, Reed G, Grunwald G, Barry M, Thompson, et al. Using electronic step counters to increase lifestyle physical activity: Colorado on the move. J Phys Act Health. 2004(1):181-90.

41. Aittasalo M, Rinne M, Pasanen M, Kukkonen-Harjula K, Vasankari T. Promoting walking among office employees - evaluation of a randomized controlled intervention with pedometers and e-mail messages. BMC Public Health. 2012 Jun 6;12:403. http://dx.doi.org/10.1186/1471-2458-12-403.

42. Lippke S, Ziegelmann J, Schwarzer R. Initiation and maintenance of physical exercise: Stage-specific effects of a planning intervention. Res Sports Med. 2004(12):221-40. http://dx.doi.org/10.1080/15438620490497567.

43. Schwarzer R, Lippke S, Ziegelmann J. Health action process approach. A research agenda at Freie Universität Berlin to examine and promote health behavior change. $Z$ Gesundh. 2008(16):157-60.

44. Schwarzer R. Modeling health behavior change: How to predict and modify the adoption and maintenance of health behaviors. Appl Psych. 2008(57):1-29.

45. Alberti KG, Eckel RH, Grundy SM, Zimmet PZ, Cleeman JI, Donato KA, et al. Harmonizing the metabolic syndrome: A joint interim statement of the International Diabetes Federation Task Force on Epidemiology and Prevention; National Heart, Lung, and Blood Institute; American Heart Association; World Heart Federation; International Atherosclerosis Society; and International Association for the Study of Obesity. Circulation. 2009 Oct 20;120(16):1640-5. http://dx.doi.org/10.1161/ CIRCULATIONAHA.109.192644.

46. Brage S, Wedderkopp N, Ekelund U, Franks PW, Wareham $\mathrm{NJ}$, Andersen LB, et al. Features of the metabolic syndrome are associated with objectively measured physical activity and fitness in Danish children: The European Youth Heart Study (EYHS). Diabetes Care. 2004 Sep;27(9):2141-8. http:// dx.doi.org/10.2337/diacare.27.9.2141.
47. Helldán A, Helakorpi S, Virtanen S, Uutela A. Health behavior and health among the Finnish adult population, spring 2012 (in Finnish with English summary). Helsinki, Finland: National Institute for Health and Welfare (THL); 2013. Report No.: 15.

48. Jain NB, Hart JE, Smith TJ, Garshick E, Laden F. Smoking behavior in trucking industry workers. Am J Ind Med. 2006 Dec;49(12):1013-20. http://dx.doi.org/10.1002/ajim.20399.

49. Klein S, Burke LE, Bray GA, Blair S, Allison DB, Pi-Sunyer $\mathrm{X}$, et al. Clinical implications of obesity with specific focus on cardiovascular disease: A statement for professionals from the American Heart Association Council on Nutrition, Physical Activity, and Metabolism: Endorsed by the American College of Cardiology Foundation. Circulation. 2004 Nov 2;110(18):2952-67. http://dx.doi.org/10.1161/01. CIR.0000145546.97738.1E.

50. Vidal J. Updated review on the benefits of weight loss. Int J Obes Relat Metab Disord. 2002 Dec;26 Suppl 4:S25-8. http:// dx.doi.org/10.1038/sj.ijo.0802215.

51. Clinical guidelines on the identification, evaluation, and treatment of overweight and obesity in adults - the evidence report. National Institutes of Health. Obes Res. 1998 Sep;6 Suppl 2:51S-209S.

52. Galani C, Schneider H. Prevention and treatment of obesity with lifestyle interventions: Review and meta-analysis. Int $\mathrm{J}$ Public Health. 2007;52(6):348-59. http://dx.doi.org/10.1007/ s00038-007-7015-8.

53. Paul-Ebhohimhen V, Avenell A. A systematic review of the effectiveness of group versus individual treatments for adult obesity. Obes Facts. 2009;2(1):17-24. http://dx.doi. org/10.1159/000186144.

54. Hedberg GE, Wikstrom-Frisen L, Janlert U. Comparison between two programmes for reducing the levels of risk indicators of heart diseases among male professional drivers. Occup Environ Med. 1998 Aug;55(8):554-61. http://dx.doi. org/10.1136/oem.55.8.554.

55. Olson R, Anger WK, Elliot DL, Wipfli B, Gray M. A new health promotion model for lone workers: Results of the Safety \& Health Involvement for Truckers (SHIFT) pilot study. J Occup Environ Med. 2009 Nov;51(11):1233-46. http://dx.doi. org/10.1097/JOM.0b013e3181c1dc7a.

56. van Wier MF, Ariens GA, Dekkers JC, Hendriksen IJ, Smid T, van Mechelen W. Phone and e-mail counselling are effective for weight management in an overweight working population: A randomized controlled trial. BMC Public Health. 2009 Jan 9;9:6. http://dx.doi.org/10.1186/1471-2458-9-6.

57. Groeneveld IF, Proper KI, van der Beek AJ, Hildebrandt VH, van Mechelen W. Lifestyle-focused interventions at the workplace to reduce the risk of cardiovascular disease - a systematic review. Scand J Work Environ Health. 2010 May;36(3):202-15. http://dx.doi.org/10.5271/sjweh.2891.

58. Verweij LM, Coffeng J, van Mechelen W, Proper KI Meta-analyses of workplace physical activity and dietary behaviour interventions on weight outcomes. Obes Rev. 2011 Jun;12(6):406-29. http://dx.doi.org/10.1111/j.1467789X.2010.00765.x.

59. Barte JC, ter Bogt NC, Bogers RP, Teixeira PJ, Blissmer B, 
Mori TA, et al. Maintenance of weight loss after lifestyle interventions for overweight and obesity, a systematic review. Obes Rev. 2010 Dec;11(12):899-906. http://dx.doi. org/10.1111/j.1467-789X.2010.00740.x.

60. Curioni CC, Lourenco PM. Long-term weight loss after diet and exercise: A systematic review. Int J Obes (Lond). 2005 Oct;29(10):1168-74. http://dx.doi.org/10.1038/ sj.ijo.0803015

61. Kukkonen-Harjula KT, Borg PT, Nenonen AM, Fogelholm MG. Effects of a weight maintenance program with or without exercise on the metabolic syndrome: A randomized trial in obese men. Prev Med. 2005 Sep-Oct;41(3-4):784-90. http:// dx.doi.org/10.1016/j.ypmed.2005.07.008.

62. Torjesen PA, Birkeland KI, Anderssen SA, Hjermann I, Holme I, Urdal P. Lifestyle changes may reverse development of the insulin resistance syndrome. The Oslo diet and exercise study: A randomized trial. Diabetes Care. 1997 Jan;20(1):26-31. http://dx.doi.org/10.2337/diacare.20.1.26.

63. Tuomilehto J, Lindstrom J, Eriksson JG, Valle TT, Hamalainen
$\mathrm{H}$, Ilanne-Parikka P, et al. Prevention of type 2 diabetes mellitus by changes in lifestyle among subjects with impaired glucose tolerance. N Engl J Med. 2001 May 3;344(18):134350. http://dx.doi.org/10.1056/NEJM200105033441801.

64. Hellenius ML, de Faire U, Berglund B, Hamsten A, Krakau I. Diet and exercise are equally effective in reducing risk for cardiovascular disease. results of a randomized controlled study in men with slightly to moderately raised cardiovascular risk factors. Atherosclerosis. 1993 Oct;103(1):81-91. http:// dx.doi.org/10.1016/0021-9150(93)90042-S.

65. McCartt AT, Hellinga LA, Solomon MG. Work schedules of long-distance truck drivers before and after 2004 hours-ofservice rule change. Traffic Inj Prev. 2008;9(3):201-10. http:// dx.doi.org/10.1080/15389580802040287.

Received for publication: 11 April 2014 